\title{
RISIKOBELEID EN KANSHOUDING
}

\author{
door Dr. C. van Dam
}

„Even (the axiom) which gets closest to excluding a ,utility of gambling", seems to be plausible and legitimate, unless a much more refined system of psychology is used than the one now available for the purposes of economics."

(John von Neumann and Oskar Morgenstern, 1944; zie blz. 28 in elke editie van hun werk.)

\begin{abstract}
"The existence of probability preferences means that the simple Von NeumannMorgenstern method of utility measurement cannot succeed. Choices between bets will be determined not only by the amount of money involved, but also by the preferences the subjects have among the probabilities involved."

(De psycholoog Ward Edwards in 1954; zie bundel Edwards/Tversky, blz. 35.)
\end{abstract}

\section{Een stukje historie}

Gaarne voldoen wij aan het verzoek van de redactie van dit maandblad om in artikel-vorm enkele van de nieuwe facetten weer te geven uit de dissertatie ${ }^{1}$ ) waarop wij in 1973 bij Prof. Dr. A. I. Diepenhorst in de economische faculteit van de Erasmus Universiteit Rotterdam zijn gepromoveerd. Bij het maken van de eerste voorbereidingen in 1966 voor het schrijven van een dissertatie gingen onze gedachten uit naar het ontwikkelen van een theorie over het nemen van investeringsbeslissingen in bedrijfshuishoudingen. Gaandeweg groeide de overtuiging dat dergelijke beslissingen op een bepaalde wijze werden genomen. Het begrip kanshouding kwam centraal te staan in onze gedachtengang. In 1970, 1971 en 1972 hebben wij met groepen managers uit het Nederlandse bedrijfsleven en studenten in de bedrijfseconomie talrijke experimenten uitgevoerd om de ontwikkelde theorie empirisch te kunnen toetsen. De resultaten hiervan zijn zodanig dat hernieuwde bezinning op het beslissingsproces, speciaal binnen bedrijfshuishoudingen gewenst lijkt. Wij waren ons reeds tijdens de studie bewust dat bij het ontwikkelen van een theorie rond het begrip kanshouding tegen gevestigde opvattingen wordt ingegaan. Wij kunnen ons dan ook voorstellen dat bij degenen die, wat de besliskunde betreft, orthodox zijn ingesteld, gedachten aan ,,ketterij" zouden kunnen boven komen. Ketterij tegen de opvattingen uit de beroemde paragraaf "The notion of utility" in het baanbrekende werk van Von Neumann en Morgenstern. Onze intenties zouden dan echter verkeerd worden beoordeeld. De bedoeling van onze studie is slechts aan te tonen dat in het feitelijke gedrag van vele besluitvormers een element valt te onderkennen, dat zich laat vangen in een kanshouding. Von Neumann en Morgenstern hebben een afgerond axiomastelsel ontworpen voor een normatieve

1) Getiteld „Beslissen in onzekerheid", een handelseditie is verschenen bij Uitgeverij Stenfert Kroese B.V. te Leiden als uitgave 51 in de serie „Bedrijfseconomische Monographieën”. Vele personen hebben ons gesteund bij het tot stand brengen van deze dissertatie. Op deze plaats willen wij ons beperken tot het danken van onze promotor voor zijn kritisch-wetenschappelijke begeleiding en van Prof. Dr. J. P. van de Geer (afdeling datatheorie van de faculteit der sociale wetenschappen van de Rijksuniversiteit Leiden) voor de constructieve en stimulerende samenwerking. 
theorie. Wij bouwden voort op hun basisconceptie aan een theorie die dichter bij de „beslispraktijk” zou kunnen staan. In aansluiting daarop hebben wij deze ideeën trachten te toetsen.

\section{Eén manager}

In onze dissertatie wordt - bij wijze van demonstratie - het gedrag van één van de deelnemers, een 37-jarige trade manager in een middelgrote handelsonderneming, bij het nemen van beslissingen in onzekerheid uitgebreid geanalyseerd. In dit artikel zal deze analyse van het gedrag van de manager als privé persoon niet worden gereproduceerd. Wèl zal worden getracht een analyse te geven van zo'n manager (de manager) in zijn zakelijke funktie.

\section{Eén serie vragen}

Om inzicht te kunnen krijgen in de houding van de deelnemers werden zij gekonfronteerd met vele series vragen. Eén van die series zou uit de onderstaande vragen hebben kunnen bestaan.

\section{Vraag 1:}

Veronderstel dat $u$, in uw funktie van manager van uw onderneming, een keuze moet maken uit twee alternatieven (investeringsmogelijkheden), waarbij het ene alternatief $u$ een kans van .90 levert op $f 4.000 .000$ winst en een kans van .10 om winst noch verlies te behalen en het andere alternatief $u$ zekerheid verschaft omtrent de grootte van de winst. Hoe groot moet dan die zekere winst zijn opdat $u$ beide alternatieven gelijkwaardig acht ${ }^{2}{ }^{2}$ )

\section{Schematisch}

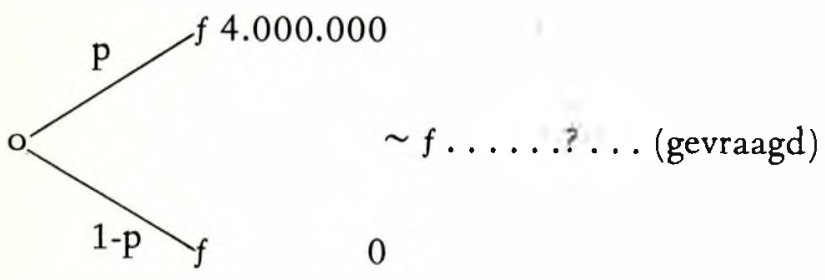

waarbij $\mathrm{p}=.90$

De overige vier vragen verschillen alleen in de grootte van $\mathrm{p}$ van de eerste vraag. De grootte van de twee gegeven resultaten is in alle vragen gelijk. In vraag 2 is $p$ gelijk aan .75

In vraag 3 is $\mathrm{p}$ gelijk aan .50

In vraag 4 is $\mathrm{p}$ gelijk aan .25

2) Het is niet noodzakelijk dat de vragen in deze vorm worden gesteld en ook niet dat de keuze van één van de alternatieven zekerheid verschaft omtrent de grootte van de te behalen winst. Een overzicht van enkele in de literatuur voorkomende technieken om risikohoudingen vast te stellen is aan hoofdstuk $\mathrm{V}$ van onze dissertatie als bijlage toegevoegd.

ma $a b$ blz. 278 
In vraag 5 is $p$ gelijk aan .10

De manager zou de volgende antwoorden kunnen hebben gegeven:

Op vraag 1: $f 2.600 .000$.

Op vraag 2: $f$ 2.000.000.

Op vraag 3: $f 1.400 .000$.

Op vraag 4: $f \quad 400.000$.

Op vraag 5: $f \quad 160.000$.

Schematisch zijn deze vragen en antwoorden als volgt weer te geven:

1.

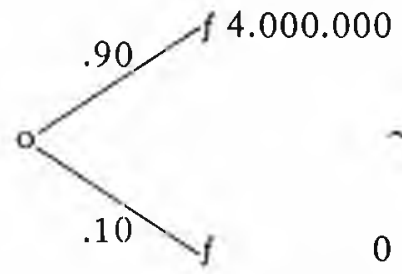

$\sim f 2.600 .000$

2.

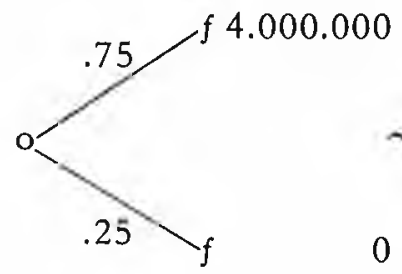

$\sim f 2.000 .000$

0

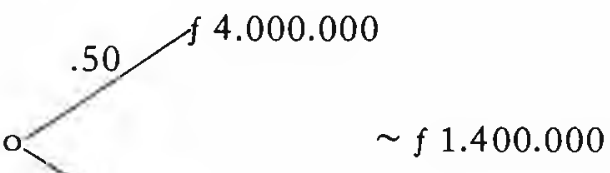

4.

3.

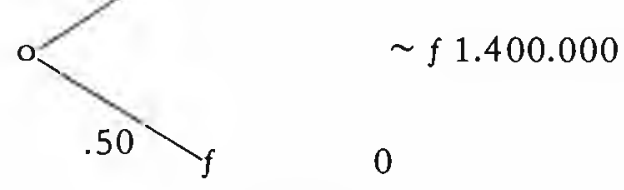

5.

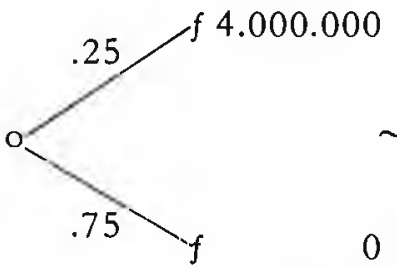

$\sim f \quad 400.000$

0

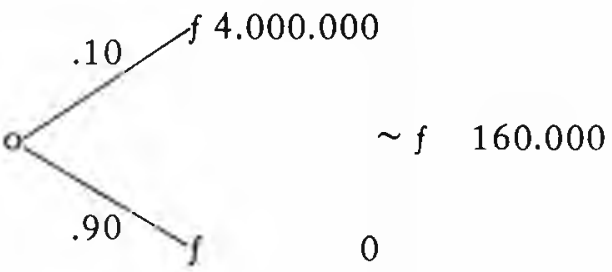




\section{De N\&M theorie}

Binnen de nutstheorie van Von Neumann en Morgenstern (N\&M theorie) ${ }^{3}$ ) kan de houding van een besluitvormer worden weergegeven door middel van een $N \& M$ kurve. Een $N \& M$ kurve is een (benaderende) grafische voorstelling van een nutsfunktie die in overeenstemming met de aan de N\&M theorie ten grondslag liggende axioma's is opgesteld. Zo'n kurve kan reeds op grond van de in paragraaf 3 opgenomen vragen en antwoorden worden getekend. Hierbij wordt als numerieke index (eenheid van nut) de utile (U) gehanteerd. Het nut is - zoals bekend - door de theorie tot op een lineaire transformatie na bepaald. Het behouden van de financiële status quo wordt op 0 utile gesteld en een winst van $f 4.000 .000$ op 1000 utilen:
$\mathrm{u}(f$
$0)=$
$0 \mathrm{U}$, of simpelweg $f$
$0=$
$0 \mathrm{U}$
$\mathrm{u}(f 4.000 .000)=1000 \mathrm{U}$, of simpelweg $f 4.000 .000=1.000 \mathrm{U}$.

Met behulp van deze twee vastgepinde punten kan worden begonnen aan het vaststellen van het verloop van de N\&M kurve. De volgende berekeningen laten zich binnen de $N \& M$ theorie uitvoeren:

$$
\begin{aligned}
u(f 2.600 .000) & =0,90 \times u(f 4.000 .000)+0,10 \times u(f 0) \\
f 2.600 .000 & =0,90 \times 1000 \mathrm{U}+0 \mathrm{U}=900 \mathrm{U} \\
\mathrm{u}(f 2.000 .000) & =0,75 \times \mathrm{u}(f 4.000 .000)+0,25 \times \mathrm{u}(f 0) \\
f 2.000 .000 & =0,75 \times 1000 \mathrm{U}+0 \mathrm{U}=750 \mathrm{U} \\
\mathrm{u}(f 1.400 .000) & =0,50 \times \mathrm{u}(f 4.000 .000)+0,50 \times \mathrm{u}(f 0) \\
f 1.400 .000 & =0,50 \times 1000 \mathrm{U}+0 \mathrm{U}=500 \mathrm{U} \\
\mathrm{u}(f \quad 400.000) & =0,25 \times \mathrm{u}(f 4.000 .000)+0,75 \times u(f 0) \\
f \quad 400.000 & =0,25 \times 1000 \mathrm{U}+0 \mathrm{U}=250 \mathrm{U} \\
\mathrm{u}(f \quad 160.000) & =0,10 \times \mathrm{u}(f 4.000 .000)+0,90 \times u(f 0) \\
\text { f } 160.000 & =0,10 \times 1000 \mathrm{U}+0 \mathrm{U}=100 \mathrm{U} .
\end{aligned}
$$

Op deze wijze zijn zeven punten vastgesteld. In tekening 1 zijn deze punten met rechte lijnstukken verbonden tot een ononderbroken lijn ${ }^{4}$ )

${ }^{3}$ ) Zie bv. J. von Neumann en O. Morgenstern, Theory of games and economic behavior, Princeton (Princeton University Press) third edition, 1953, blz. 15-31.

4) Een verklaring voor het met rechte lijnstukken verbinden van de punten en het niet tekenen van een geheel vloeiend verlopende curve door de punten, staat in onze dissertatie op blz. 15.

$m a b$ blz. 280 


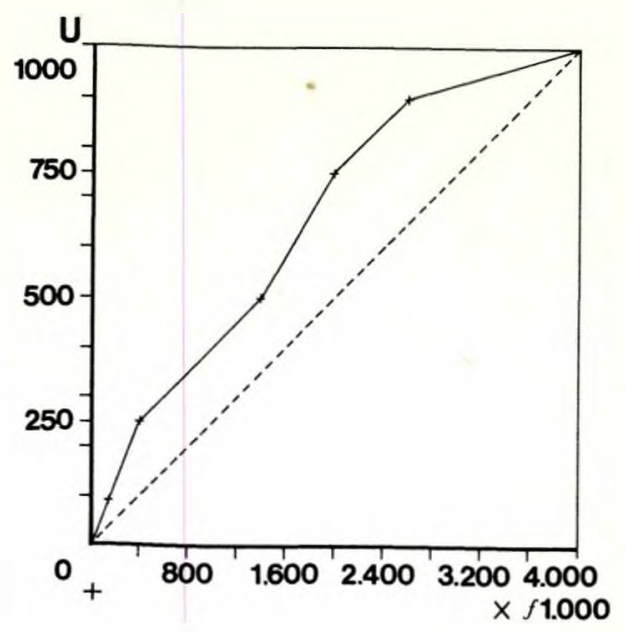

Tekening 1: NGM kurve van de manager van f 0 tot $f 4.000 .000$ op grond van vijf vragen.

\section{Discrepanties}

Telkens als de deelnemers aan de experimenten met andere vragen worden gekonfronteerd blijken de punten die uit de vragen en antwoorden kunnen worden afgeleid niet op een reeds vastgelegde N\&M kurve te liggen. De afstanden tussen de punten en de reeds vastgelegde $N \& M$ kurve zijn zo groot dat de oorzaak van het ontstaan van de discrepanties noch schijnt te moeten worden gezocht in het eventueel afronden bij het antwoorden door de deelnemers, noch in de manier waarop de punten zijn verbonden tot een kurve.

In tekening 2 zijn vierendertig punten weergegeven zoals ze uit antwoorden van de manager zouden kunnen zijn afgeleid. De kurve uit tekening 1 is ook ingetekend.

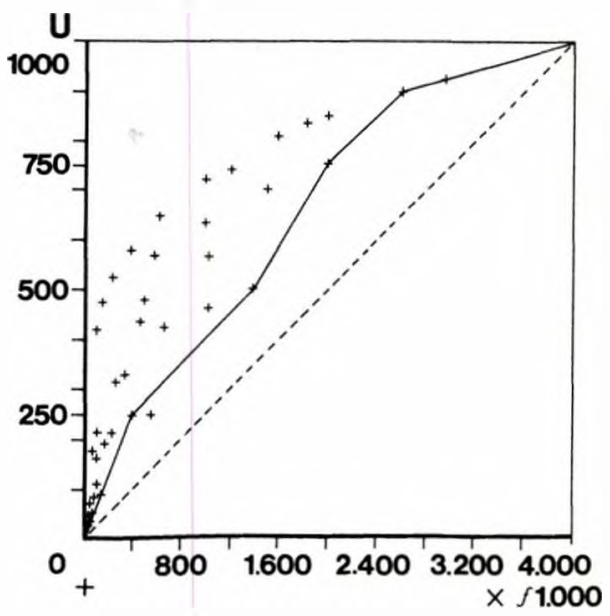

Tekening 2: NEM kurve van de manager van $f 0$ tot $f 4.000 .000$ op grond van vijf vragen met nog 34 andere punten. 
Een analyse van de puntenwolk in tekening 2 moet tot de conclusie leiden dat de manager zich binnen de NEM theorie inconsistent gedraagt. Aanhangers van de N\&M theorie poneren in zo'n geval dat de manager zou moeten worden overtuigd van het feit dat hij zich inconsistent gedraagt ${ }^{5}$ ) (althans binnen de $\mathrm{N} \& \mathrm{M}$ theorie). Hetgeen volgens hen zou moeten leiden tot het met elkaar (en daarmede met de N\&M theorie) in overeenstemming brengen van de antwoorden door de manager. Onze evvaring met de deelnemers aan onze experimenten is echter, dat $\mathrm{zij}$ - zonder dat er sterke aandrang op hen wordt uitgeoefend - niet kunnen worden overtuigd van inconsistent gedrag. Het ontstaan van de discrepanties schijnt een andere oorzaak te hebben (de inhoud van het begrip (in)consistent gedrag is afhankelijk van het axiomastelsel dat wordt gehanteerd).

\section{Het primaire karakter van kansverdelingen}

Een nadere analyse van de antwoorden die de manager op de vragen heeft gegeven schijnt de conclusie te wettigen dat in de houding van de manager een element valt te onderkennen dat afhankelijk is van het primaire karakter van de kansverdelingen waarmee hij wordt gekonfronteerd. Dit gaat eveneens op voor de meeste andere deelnemers aan de experimenten.

Onder het primaire karakter van een kansverdeling verstaan wij het gedeelte van het karakter van de verdeling dat wordt bepaald door

a. de grootte van de kansen op de resultaten uit de kansverdeling;

$b$. het positief, nul of negatief zijn van elk van de resultaten uit de kansverdeling.

De (absolute) grootte van de resultaten uit de kansverdeling zijn dus niet van invloed op het primaire karakter van de verdeling.

Von Neumann en Morgenstern hebben bij het ontwerpen van hun axiomastelsel bewust bovengenoemd element in de houding van besluitvormers buitengesloten. Daar de invloed die deze auteurs nog steeds hebben op het denken over beslissen en beslissingsgedrag moeilijk kan worden overschat, is grote omzichtigheid geboden. De introduktie van het begrip kanshouding kan ons echter verder helpen bij de analyse.

\section{Het begrip kanshouding}

Nadat een besluitvormer alle alternatieven waarmee hij wordt gekonfronteerd heeft beoordeeld, kunnen de alternatieven worden gerangschikt naar aantrekkelijkheid voor de betreffende besluitvormer. We veronderstellen dat deze ordening kan worden beschreven door een funktie. Binnen de $N \& M$ theorie is dat

$\mathrm{u}\left(\mathrm{p} \mathrm{R}_{\mathrm{h}},(1-\mathrm{p}) \mathrm{R}_{\mathrm{i}}\right)=\mathrm{p} \cdot \mathrm{u}\left(\mathrm{R}_{\mathrm{h}}\right)+(1-\mathrm{p}) \cdot \mathrm{u}\left(\mathrm{R}_{\mathrm{i}}\right)$ waarbij $\left(p R_{h},(1-p) R_{i}\right)$ staat voor het alternatief

\footnotetext{
$\left.{ }^{5}\right)$ Een uitvloeisel van de gedachte dat de $\mathrm{N} \& \mathrm{M}$ theorie door hen wordt gezien als „a guide to consistent action", R. Duncan Luce and Howard Raiffa, Games and decisions, introduction and critical survey, New York/London (John Wiley and Sons/Chapman and Hall), 1957, blz. 32.
}

$m a b$ blz. 282 


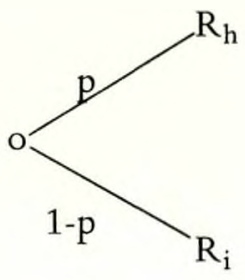

Binnen onze theorie heeft de funktie als algemene gedaante:

$n\left(p R_{h},(1-p) R_{i}\right)=g(p) \cdot n\left(R_{h}\right)+(1-g(p)) \cdot n\left(R_{i}\right)$

indien $R_{h}>R_{i} \geqslant f 0$.

De funktie $g(p)$ noemen wij de kanshouding van de besluitvormer. De grootte van $g(p)$ hebben wij de naam subjektief gewicht (van $p$ ) gegeven. De funktie $n\left(R_{x}\right)$ noemen wij zijn nutilefunktie $(x=h, i, \ldots) \cdot n\left(R_{h}\right)$ noemen wij de nutilewaarde van $R_{h}$; als numerieke index wordt de nutile $(N)$ gehanteerd. De houding van een besluitvormer kan binnen de N\&M theorie worden weergegeven door middel van een $N \& M$ kurve. De houding van een besluitvormer wordt binnen onze theorie weergegeven door middel van de kombinatie kanshouding/nutilekurve (nutilefunktie).

Om verkeerde interpretaties te voorkomen zij duidelijk gesteld dat het veronderstellen van het bestaan van een kanshouding niet betekent dat wordt verondersteld dat een besluitvormer ,objektieve" kansen vervangt door „subjektieve" kansen. Met een kanshouding wordt wél (een gedeelte van) de risikohouding van een besluitvormer tot uitdrukking gebracht.

\section{De manager en zijn kanshouding}

Voor de manager blijkt in zijn zakelijke funktie een kanshouding te kunnen worden vastgesteld waaruit de volgende subjektieve gewichten voortvloeien:

\begin{tabular}{|c|c|}
\hline kans op winst & subjektief gewicht $(g(p))$ \\
\hline .90 & 0,67 \\
.75 & 0,56 \\
.50 & 0,42 \\
.25 & 0,15 \\
.10 & 0,07 \\
\hline
\end{tabular}

Er wordt gesteld, dat
$n(f$
$0)=$
$0 \mathrm{~N}$ of simpelweg $f$
$0=$
$0 \mathrm{~N}$
$\mathrm{n}(f 4.000 .000)=1000 \mathrm{~N}$ of simpelweg $f 4.000 .000=1.000 \mathrm{~N}$. 
De volgende berekeningen laten zich nu binnen onze theorie uitvoeren op grond van de in paragraaf 3 weergegeven antwoorden van de manager op vijf vragen:

$\mathrm{n}(f 2.600 .000)=0,67 \times \mathrm{n}(f 4.000 .000)+0,33 \times \mathrm{n}(f 0)$

$$
f 2.600 .000=0,67 \times 1000 \mathrm{~N}+0 \mathrm{~N}=670 \mathrm{~N}
$$

$\mathrm{n}(f 2.000 .000)=0,56 \times \mathrm{n}(f 4.000 .000)+0,44 \times \mathrm{n}(f 0)$

f $2.000 .000=0,56 \times 1000 \mathrm{~N}+0 \mathrm{~N}=560 \mathrm{~N}$

$\mathrm{n}(f 1.400 .000)=0,42 \times \mathrm{n}(f 4.000 .000)+0,58 \times \mathrm{n}(f 0)$

$$
\text { f } 1.400 .000=0,42 \times 1000 \mathrm{~N}+0 \mathrm{~N}=420 \mathrm{~N}
$$

$\mathrm{n}(f \quad 400.000)=0,15 \times \mathrm{n}(f 4.000 .000)+0,85 \times \mathrm{n}(f 0)$

f $400.000=0,15 \times 1000 \mathrm{~N}+0 \mathrm{~N}=150 \mathrm{~N}$

$\mathrm{n}(f \quad 160.000)=0,07 \times \mathrm{n}(f 4.000 .000)+0,93 \times \mathrm{n}(f 0)$

f $160.000=0,07 \times 1000 \mathrm{~N}+0 \mathrm{~N}=70 \mathrm{~N}$.

Evenals binnen de N\&M theorie kunnen de verkregen zeven punten tot een ononderbroken lijn (nutilekurve) worden verbonden. Zie tekening 3.

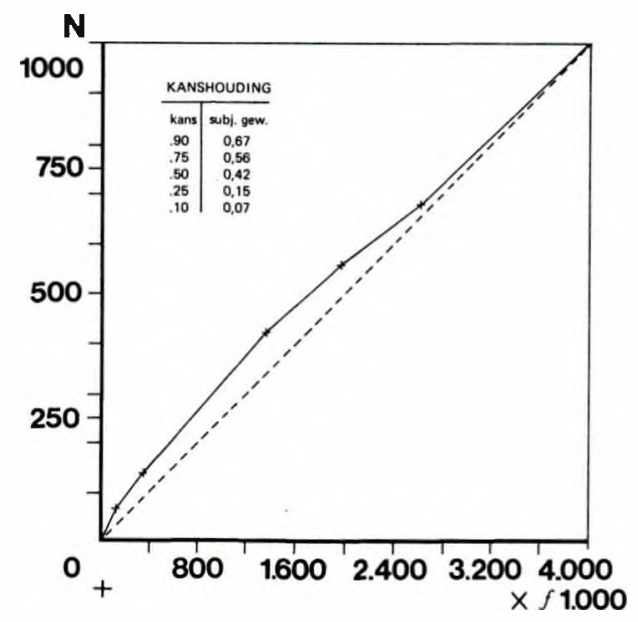

Tekening 3: Nutilekurve van de manager van $f 0$ tot $f 4.000 .000$ op grond van vijf vragen.

De 34 punten die binnen onze theorie kunnen worden afgeleid uit dezelfde vragen en antwoorden als die ten grondslag liggen aan de punten in tekening 2 , zijn weergegeven in tekening 4 ; tezamen met de kurve uit tekening 3. 


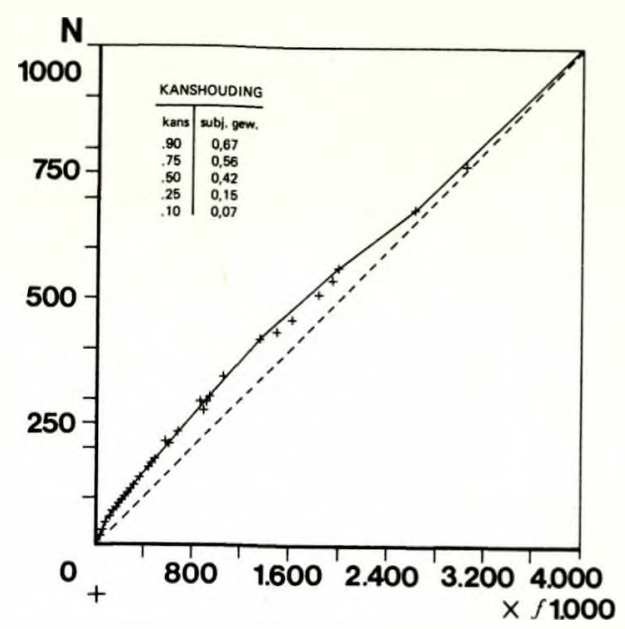

Tekening 4: Nutilekurve van de manager van f 0 tot $f 4.000 .000$ op grond van vijf vragen met nog 34 andere punten.

Uit een vergelijking van de puntenwolken in de tekeningen 2 en 4 blijkt duidelijk dat met behulp van een kombinatie kanshouding/nutilekurve het gedrag van de manager beter kan worden beschreven dan met alleen een N\&M kurve. Een onderzoek op grotere schaal lijkt dan ook gerechtvaardigd en is uitgevoerd.

\section{Het vaststellen van een risikobeleid}

Om de ontwikkelde ideeën praktische relevantie te geven moet na het uitvoeren van experimenten met managers allereerst met de managers worden gepraat. De managers moeten bewust worden gemaakt van de betekenis van de vastgestelde houdingen. Zodra elke manager zich zelf kan terugvinden in de voor hem vastgestelde houding, eventueel na enige modificaties, kunnen de managers met elkaars houding worden gekonfronteerd. Een groep managers zal dan tot overeenstemming moeten komen over de risikohouding (in casu kombinatie kanshouding/nutilekurve) die voor hun onderneming opportuun wordt geacht. Hiermee is een risikobeleid van een (deel van een) onderneming vastgesteld. Een periodieke gedachtenwisseling hierover (c.q. aanpassing ervan) is echter noodzakelijk. Het beleid kan ook nog gedifferentieerd worden al naar gelang de aard en de reikwijdte van de te nemen beslissingen. Het is goed voorstelbaar dat er meerdere kanshoudingen worden vastgesteld al naar gelang het gaat om kleine, middelgrote of grote positieve of negatieve resultaten. Is eenmaal een risikobeleid expliciet gemaakt, dan kunnen beslissingsbevoegdheden beter worden gedelegeerd en vele beslissingen sneller worden genomen, waardoor meer tijd beschikbaar komt voor het zich bezig houden met eerdere fasen van het beslissingsproces. 
Carl S. Spetzler ${ }^{6}$ ) heeft in de jaren zestig geëxperimenteerd met groepen managers om tot een gemeenschappelijk vastgesteld risikobeleid te kunnen komen. Hij deed dat echter binnen de N\&M theorie. Wij hebben dit ook gedaan met groepen managers en groepen studenten; zowel binnen de N\&M theorie als binnen onze theorie.

\section{Slotbeschouwing}

In het tweede deel van onze dissertatie worden twee methoden ontwikkeld om risikohoudingen vast te stellen, de simultane meetmethode en de tweestapsmethode. Met deze methoden worden allereerst (risiko)houdingen vastgesteld binnen de $N \& M$ theorie en enkele varianten van onze theorie. Daarna worden deze houdingen gebruikt om het gedrag van de deelnemers te voorspellen. Hierbij komen ook andere kansverdelingen aan de orde dan de tweepuntsverdelingen die in dit artikel terecht zijn gekomen.

In dit artikel zijn slechts enkele van de facetten van onze studie belicht. Daarbij moesten af en toe grote stappen worden genomen. Hopelijk voelen vele lezers zich thans gemotiveerd om aan het lezen van „Beslissen in onzekerheid" te beginnen. Dat dit moge leiden tot „NUTTIGE” diskussies.

\section{Aanbevolen literatuur}

C. S. Spetzler, The explicit consideration of uncertainty in capital investment analysis. Ph. D. thesis, Graduate School of Illinois Institute of Technology, Chicago, Ill, 1968.

C. S. Spetzler, Establishing a corporate risk policy, Proceedings Nineteenth Annual Institute Conference and Convention. American Institute of Industrial Engineers, New York, 1968, blz. 103-112,

R. O. Swalm, Utility theory-insights into risk taking. Harvard Business Review, vol. 44 (no. 6), 1966, blz. 123-137.

W. Edwards and A. Tversky (eds.), Decision making - selected readings. Harmondsworth (Penguin Books), 1967.

P. Lorange and V. D. Norman, How attitudes towards risk influence investment decisions. European Business, no. 33, Spring 1972, blz. 71-81.

P. Slovic, Psychological study of human judgment: implications for investment decision making. Journal of Finance, vol. XXVII, (Sept.) 1972, blz. 779-800.

C. van Dam, Beslissen in onzekerheid. Leiden (Stenfert Kroese), 1973.

C. van Dam, Beslissen: nut en kanshouding. Maandblad Bedrijfskunde, 45e jaargang, 1973 , blz. 100-105; opgenomen in: C. van Dam en P. W. Moerland (red.), Beslissen, Deventer (Kluwer), 1974, blz. 44-53.

6) Zie de literatuurlijst aan het einde van dit artikel.

$m a b$ blz. 286 